\title{
TODA VIDA É UMA OBRA \\ IMAGENS DE ARTETERAPIA EM UM ANTIGO HOSPÍCIO
}

\section{MÁRIO EUGÊNIO SARETTA ${ }^{1}$}

Esta narrativa fotográfica foi realizada na Oficina de Criatividade do Hospital Psiquiátrico São Pedro (criada em 1990, em Porto Alegre, tendo como inspiração o trabalho da psiquiatra Nise da Silveira), onde realizei longo período de pesquisa etnográfica. As fotografias foram feitas durante a filmagem de Epidemia de Cores, documentário dirigido por mim e lançado em 2016 . Pouco tempo depois, o espaço foi interditado por risco de desabamento e os ateliês, que se situavam na estrutura física do antigo manicômio, tiveram de ser transferidos para um novo local dentro da própria instituição.

Clemente e Natália, retratados nas fotografias, tinham o hospital psiquiátrico como local de moradia e eram participantes assíduos da Oficina de Criatividade. Clemente, que já faleceu, sentava-se sempre no mesmo local, de onde podia enxergar outros moradores chegando para as atividades. Natália continua frequentando a Oficina de Criatividade e ainda reside no hospital psiquiátrico. Suas obras integraram algumas exposições coletivas, como a intitulada Vidas do Fora: Eu Sou Você, realizada no próprio local pelo Museu da Universidade Federal do Rio Grande do Sul em parceria com o hospital psiquiátrico em 2010, e, mais recentemente, a exposição Lugares do Delírio, ocorrida em 2017 no Museu de Arte do Rio. Nessa ocasião, ela esteve presente na inauguração, o que oportunizou que viajasse de avião e conhecesse o mar. Contou-me que o que mais havia gostado na viagem havia sido ver as suas obras na exposição.

Na escolha dessa narrativa, busquei contemplar a função terapêutica que é uma proposição da Oficina de Criatividade enquanto um espaço apresentado como arteterapia. Sem a reivindicação artística ou de um acesso privilegiado ao inconsciente por meio do conteúdo das obras, meu interesse está na capacidade dos ateliês propiciarem a pessoas submetidas a uma instituição-total (GOFFMAN, 2007) possibilidades de recompor uma corporeidade existencial por meio da criação (GUATTARI, 1992, p.17). Nesse sentido, as imagens são de um acontecimento. Trata-se de obra de vida. 

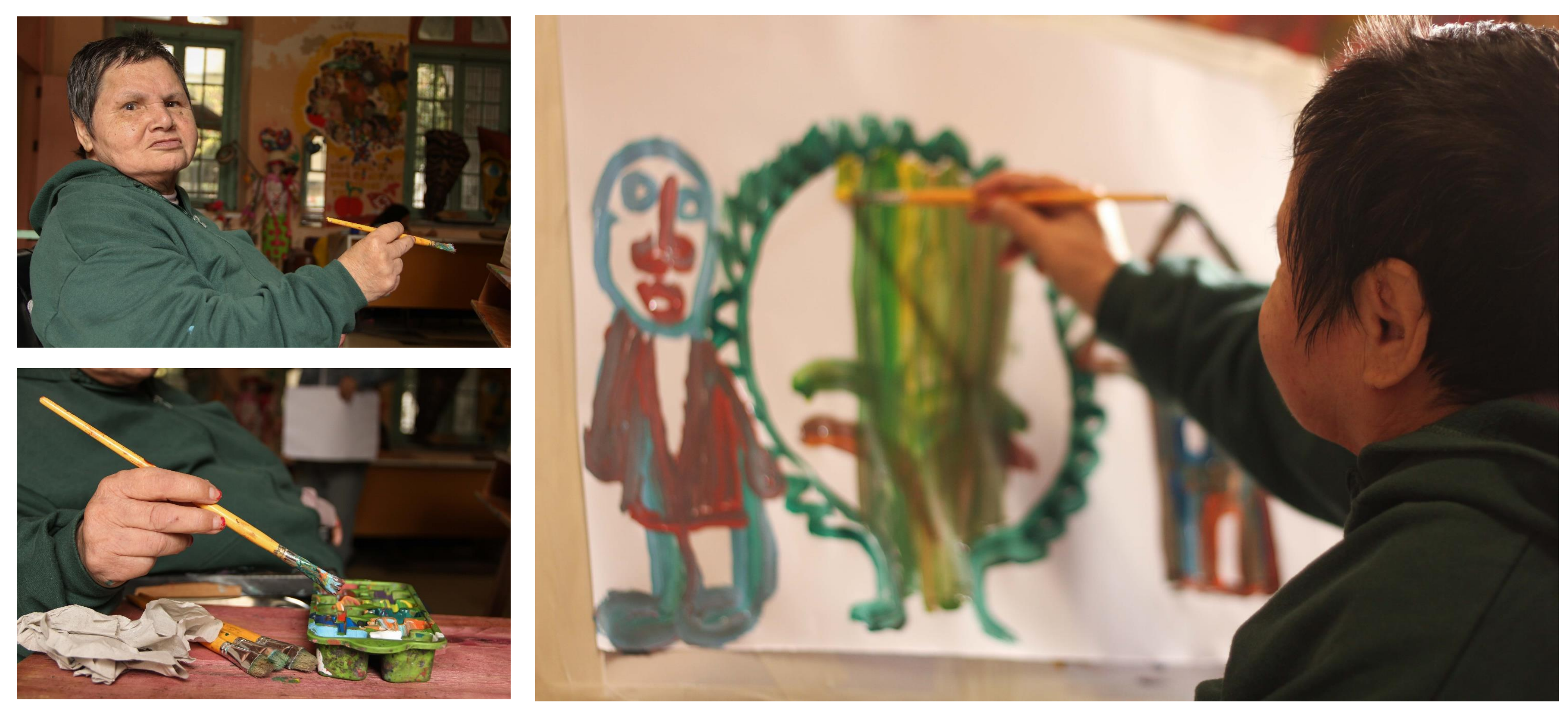


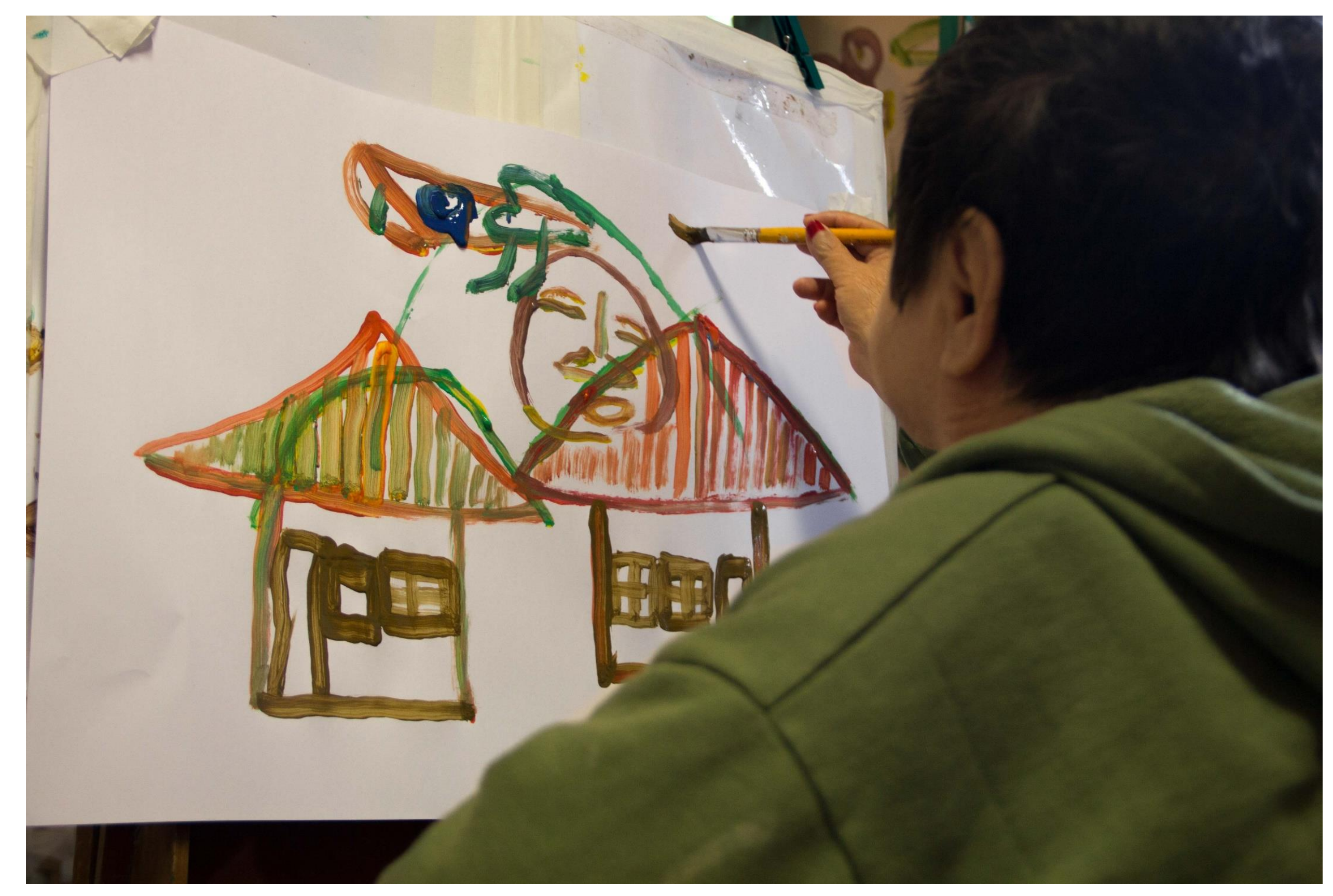




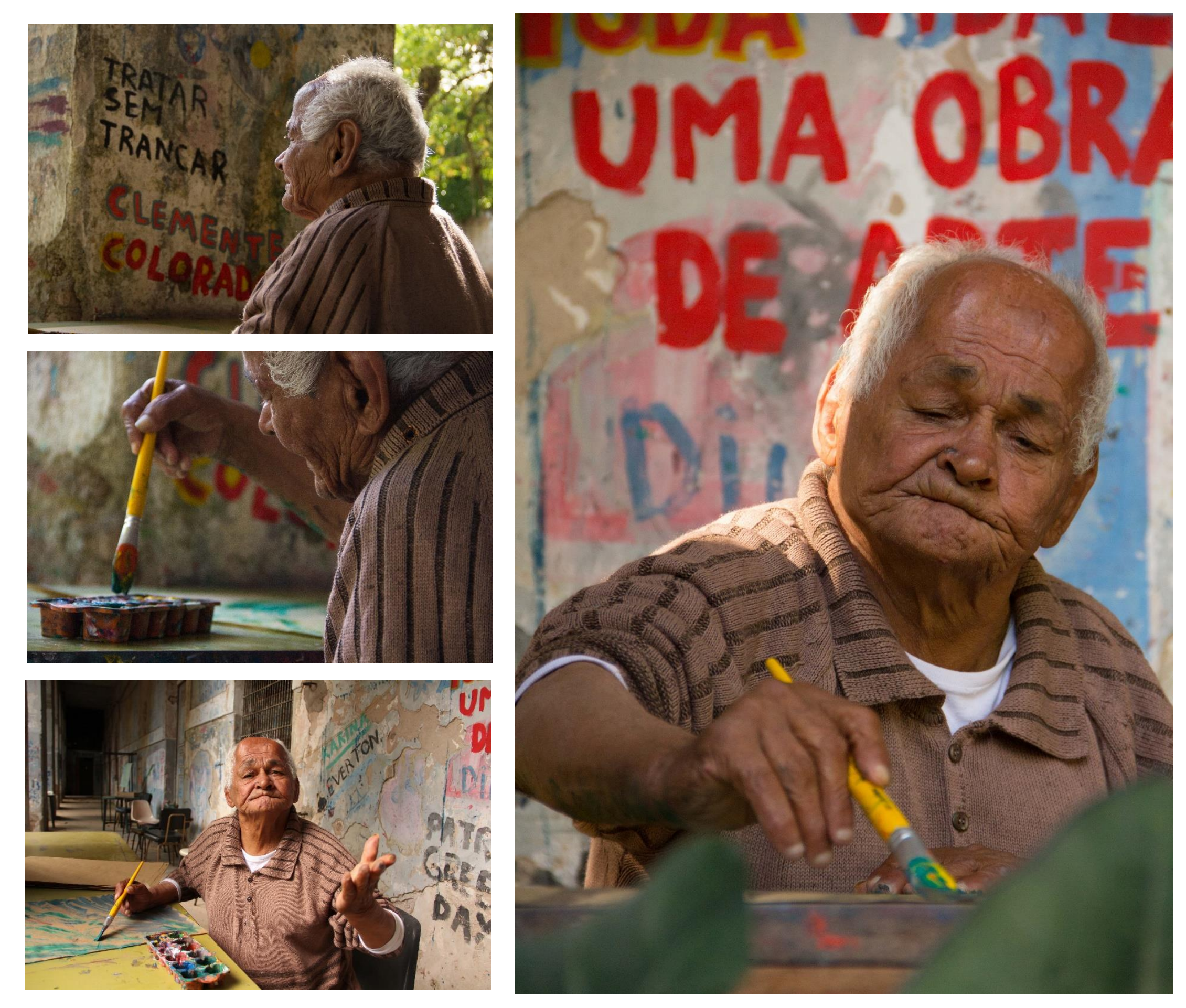




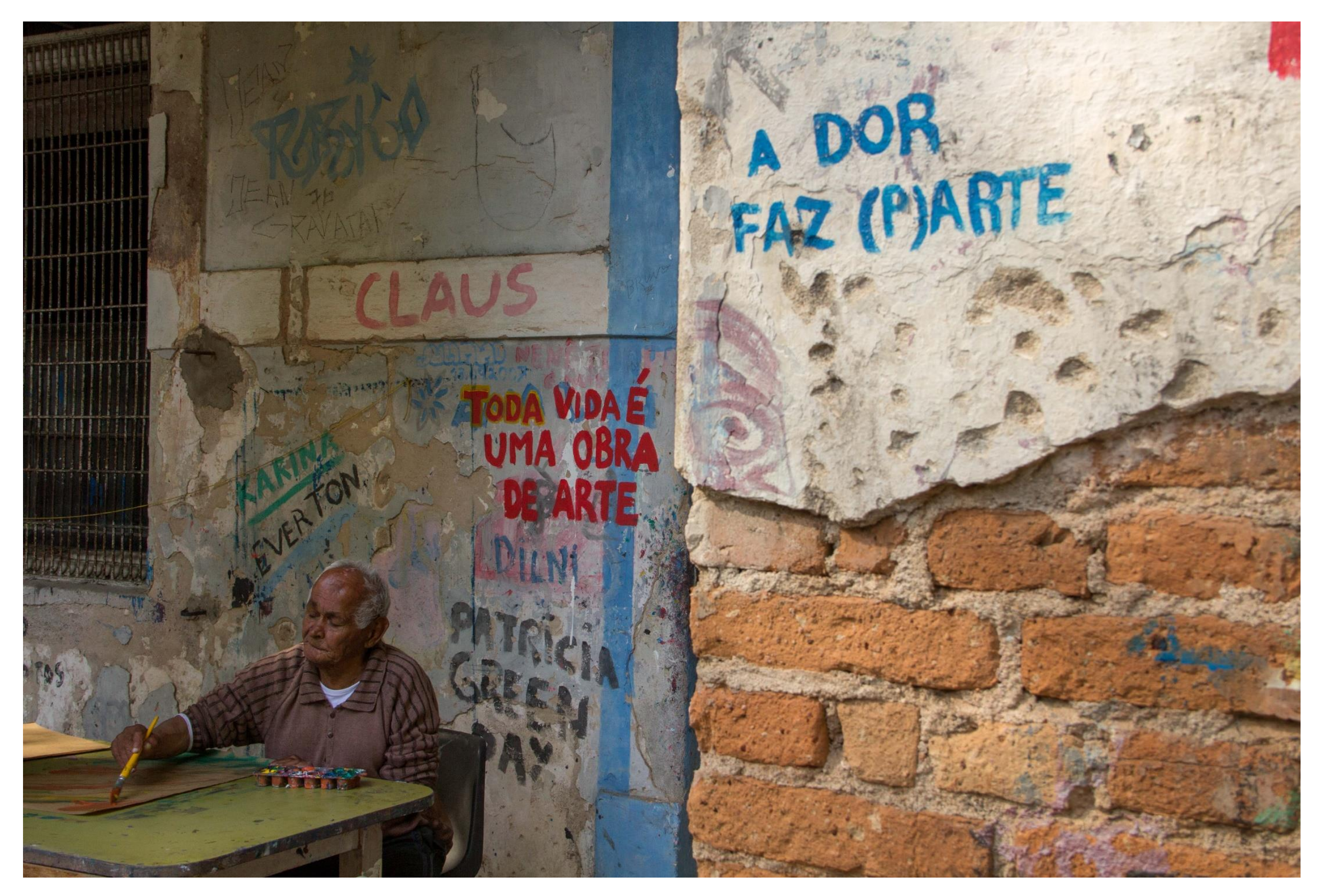


EPIDEMIA de Cores. Direção e Produção: Mário Eugênio Saretta, HD, 2016 (70min). GOFFMAN, Erving. Prisões, manicômios e conventos. São Paulo: Editora Perspectiva, 2007. GUATTARI, Félix. Caosmose. um Novo Paradigma Estético. Rio de Janeiro: Editora 34, 1992. 